Case Report

\title{
The Power of a Soccer Ball: A Traumatic Open Finger Dislocation-A Rare Case Presentation
}

\author{
Turan Cihan Dülgeroğlu, ${ }^{1}$ Hasan Metineren, ${ }^{1}$ Ekrem Aydın, ${ }^{1}$ and Ayşegül Dülgeroğlu ${ }^{2}$ \\ ${ }^{1}$ Department of Orthopaedics and Traumatology, Dumlupinar University School of Medicine, 43270 Kutahya, Turkey \\ ${ }^{2}$ Department of Radiology, Evliya Çelebi Educational Research Hospital, 43050 Kutahya, Turkey
}

Correspondence should be addressed to Turan Cihan Dülgeroğlu; dr_turancihan@hotmail.com

Received 28 April 2015; Revised 4 August 2015; Accepted 6 August 2015

Academic Editor: George Mouzopoulos

Copyright (C) 2015 Turan Cihan Dülgeroğlu et al. This is an open access article distributed under the Creative Commons Attribution License, which permits unrestricted use, distribution, and reproduction in any medium, provided the original work is properly cited.

Proximal interphalangeal joint dislocations are injuries observed frequently and caused by axial loading on the finger in the extension. In this paper we present a traumatic open finger dislocation due to a ball hitting a wrestler. It was successfully treated with reduction and the volar plate and collateral bond fixation were applied with absorbable sutures.

\section{Introduction}

Proximal interphalangeal joint dislocations are injuries observed frequently and caused by axial loading on the finger in the extension [1]. As a result of such traumas applied on the finger which is in hyperextension, many injuries may occur like incomplete volar plate injury, collateral bond injury, extension or flexor tendon rupture, and traumatic extensor tendon dislocation. Volar plate rupture in the mid-phalanx or bone fractures with small fragments may also be observed [2]. Closed reduction, external fixation, splint, pinning, open reduction, and volar plate fixation may be applied in the treatment. The primary aim of the treatment after such injuries is the stability of the joint. If such injuries are not treated well or are neglected, they may cause pain in the finger, stiffness, degenerative arthritis, and instabilities in the future [3].

\section{Case Report}

22-year-old male patient from Turkey, who was a wrestler, applied to the Emergency Service with joint open dislocation in finger due to a ball hitting his extension in his right hand, while he was playing football as a goalkeeper without gloves in an astro pitch. He had a proximal interphalangeal joint dislocation injury in his hand in the 4th finger in radial side stretching to the proximal phalanx and accompanied by nearly 1,5 centimeters laceration (Figures 1, 2, and 3). There was no neurovascular deficit in the finger of the patient.
Washing and debridement were applied to the open joint of the patient. There was damage in the volar plate and in radial side collateral ligament. The volar plate and collateral bond fixation were applied with absorbable 5-0 PDS (PDS, Ethicon, San Angelo, TX, USA) sutures and with no need for periosteum pull-out sutures with the modified Kessler suture technique. After the reduction, the patient was kindly taken to the PIP joint extension application and the joint stability and neurovascular examinations were performed. Postoperative proximal interphalangeal joint was stable and to prevent joint from Kirschner wire traumas, Kirschner wire fixation was not implemented (Figures 4 and 5). Dorsal aluminum split was applied to the patient in postoperative 30 degrees flexion. The patient was given a postoperative antibiotherapy and wound area was examined. In the 4 th week he was taken to the physical treatment program. At the end of the 6th month, the patient was able to start his active sport life fully again. Finger's flexion and extention range of motion was full degrees (Figure 6). However there was no stiffness, pain, or chronic instability. In addition, postoperative scarring was minimal.

\section{Discussion}

The main aim in PIP joint traumatic dislocations must be a concentric joint stability. Patients and doctors strive for obtaining perfect results. Many patients need rehabilitation treatment in order to reach the full ROM capacity again. 


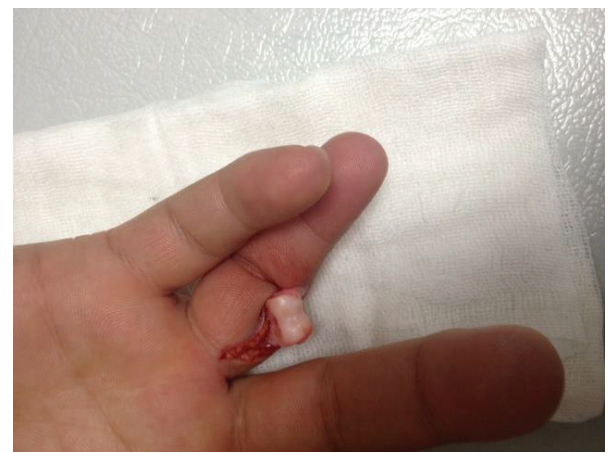

FIGURE 1: Injury showing open finger dislocation.

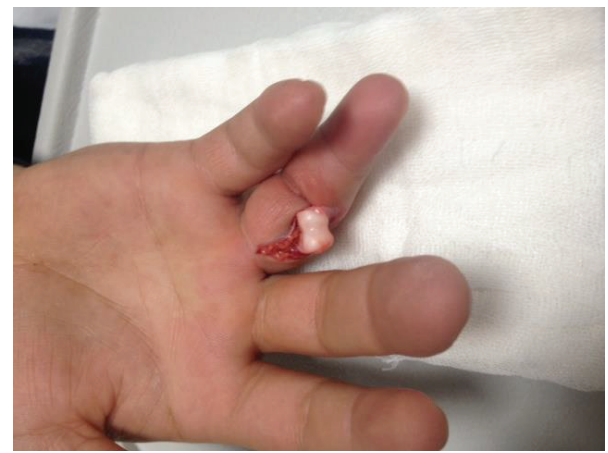

FIGURE 2: Injury showing open finger dislocation.

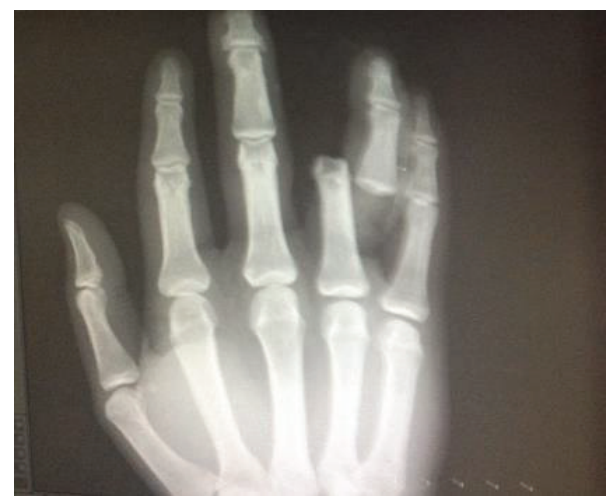

FIGURE 3: X-ray showing finger dislocation.

Splinting in extension may be applied in these patients as a classic textbook knowledge; however, a joint staying in a long-term instable position which is not anatomical will cause contractures in the joint and may be predisposed to resistant and extra injuries in further time [4]. In PIP traumatic joint dislocations, closed reduction-fixation with $\mathrm{K}$-wire, open reduction-fixation with $\mathrm{K}$-wire, cerclage wire, volar plate arthroplasty, external fixation, and many other treatment methods have been defined [5]. Each treatment method has its own advantages and disadvantages within itself. In our case, since the patient had a joint open dislocation, the volar plate and collateral bond were fixed with absorbable sutures. However, if nonabsorbable sutures were used in the patient

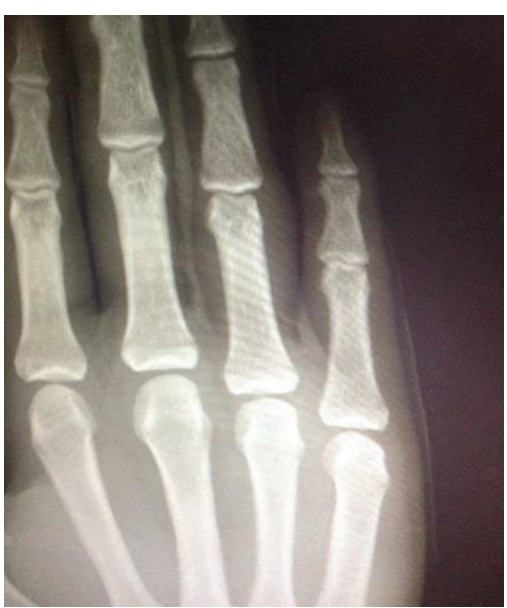

FIGURE 4: X-ray showing reduced finger.

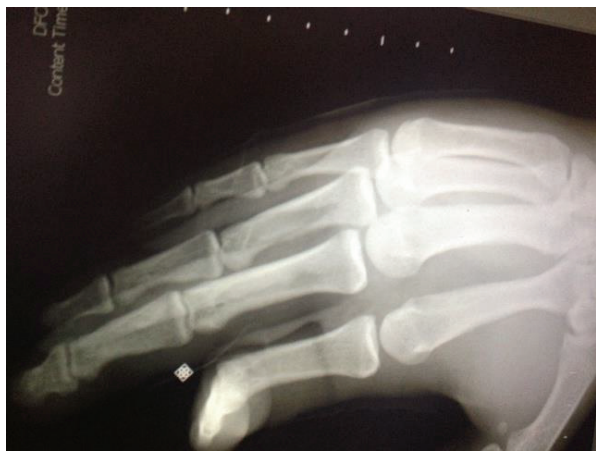

FIGURE 5: X-ray showing reduced finger.

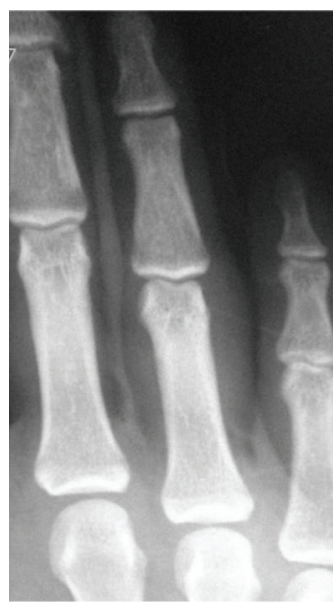

Figure 6: At the end of 6 months, X-ray showing joint congruity.

for treatment, fibrosis, granuloma, and other similar complications could be observed due to the reaction of the body to suture materials [6].

In this case report, we explained the case of an open PIP joint injury developed in the hand upon a football hit, while the patient, who dealt with wrestling, was playing football as the goalkeeper without wearing gloves. Although these types 
of injuries may be observed in astro pitch matches, no case reports were observed upon the literature scan talking about open PIP joint dislocation due to a ball hitting. In our opinion, the patient's playing as the goalkeeping without wearing gloves may be one of the reasons that triggered the PIP joint open dislocation. In such games, if the sportsmen start the games with proper equipment, the damage that may occur in their bodies may be decreased to a minimum level and even be avoided.

\section{Ethical Approval}

All procedures were in accordance with the ethical standards of the institutional and/or national research committee.

\section{Consent}

Written informed consent was obtained from the patient for publication of this case report and accompanying images.

\section{Conflict of Interests}

The authors declare that they have no conflict of interests.

\section{Authors' Contribution}

Turan Cihan Dülgeroğlu, Hasan Metineren, Ekrem Aydın, and Ayşegül Dülgeroğlu, contributed equally to this work; Turan Cihan Dülgeroğlu did this patient's care, including surgery and follow-up; Hasan Metineren A drafted and revised the paper; Ekrem Aydın and Ayşegül Dülgeroğlu assessed the quality of the paper and wrote and edited in English.

\section{References}

[1] C. Y. Ng and C. W. Oliver, "Fractures of the proximal interphalangeal joints of the fingers," The Journal of Bone and Joint Surgery-Volume B, vol. 91, no. 6, pp. 705-712, 2009.

[2] A.-P. C. Weiss, "Cerclage fixation for fracture dislocation of the proximal interphalangeal joint," Clinical Orthopaedics and Related Research, no. 327, pp. 21-28, 1996.

[3] S. K. O'Rourke, S. Gaur, and N. J. Barton, "Long-term outcome of articular fractures of the phalanges: an eleven year follow up," The Journal of Hand Surgery, vol. 14, no. 2, pp. 183-193, 1989.

[4] M. J. Botte, J. L. W. Davis, B. A. Rose et al., "Complications of smooth pin fixation of fractures and dislocations in the hand and wrist," Clinical Orthopaedics and Related Research, vol. 276, no. 3, pp. 194-201, 1992.

[5] R. T. Ruland, C. J. Hogan, D. L. Cannon, and J. F. Slade, "Use of dynamic distraction external fixation for unstable fracturedislocations of the proximal interphalangeal joint," Journal of Hand Surgery, vol. 33, no. 1, pp. 19-25, 2008.

[6] A. Pabari, S. Iyer, O. A. Branford, and A. P. Armstrong, "Palmar granuloma following flexor tendon repair using Ticron: a case for absorbable suture material?" Journal of Plastic, Reconstructive \& Aesthetic Surgery, vol. 64, no. 3, pp. 409-411, 2011. 


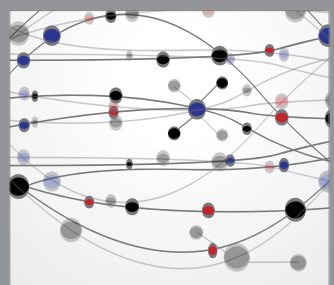

The Scientific World Journal
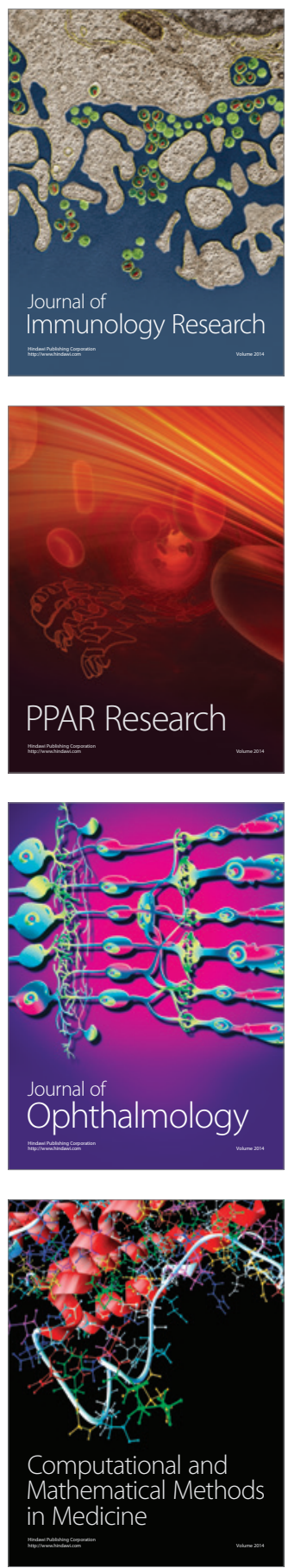

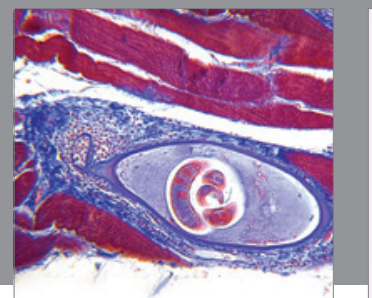

Gastroenterology

Research and Practice
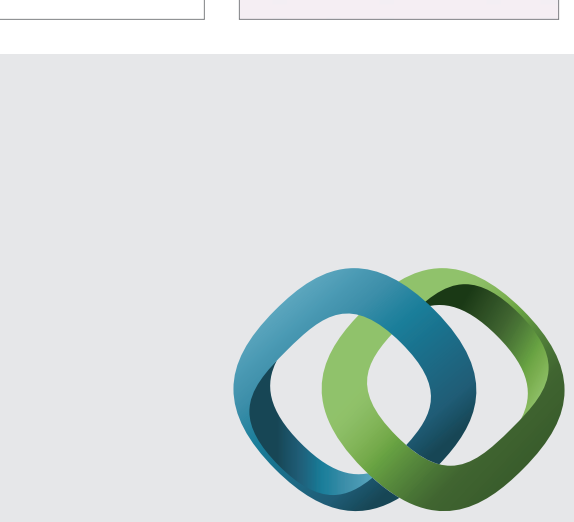

\section{Hindawi}

Submit your manuscripts at

http://www.hindawi.com
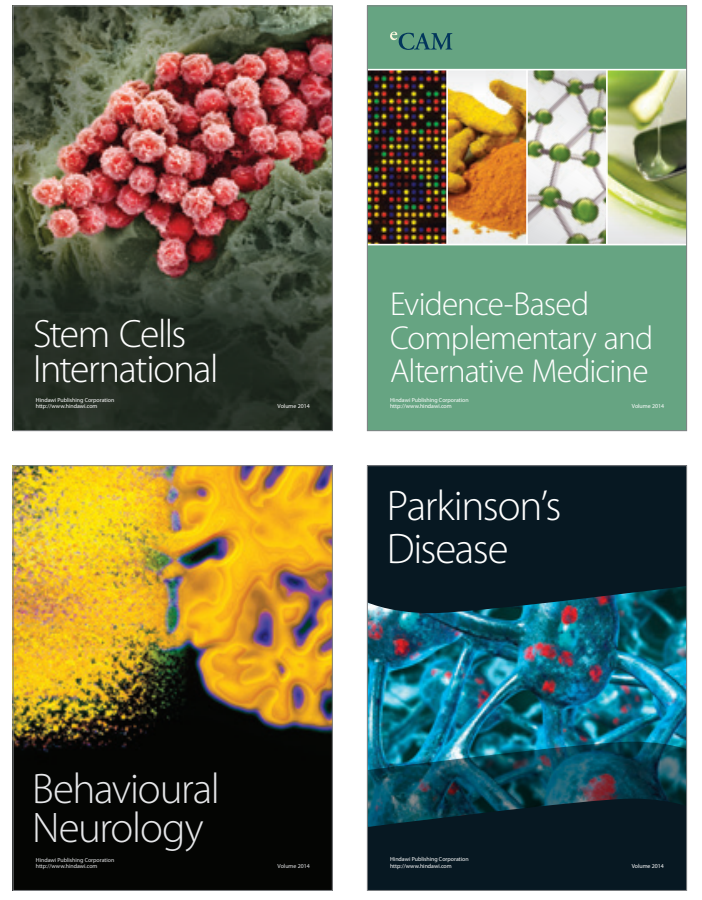
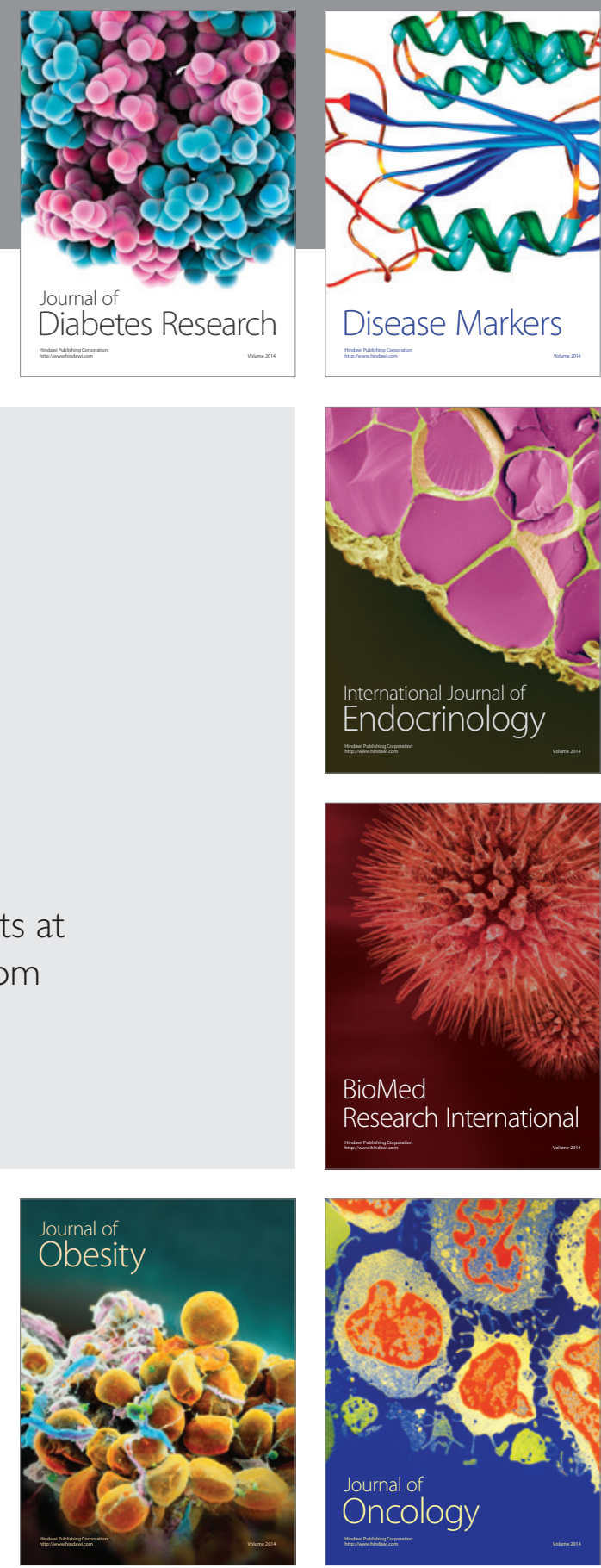

Disease Markers
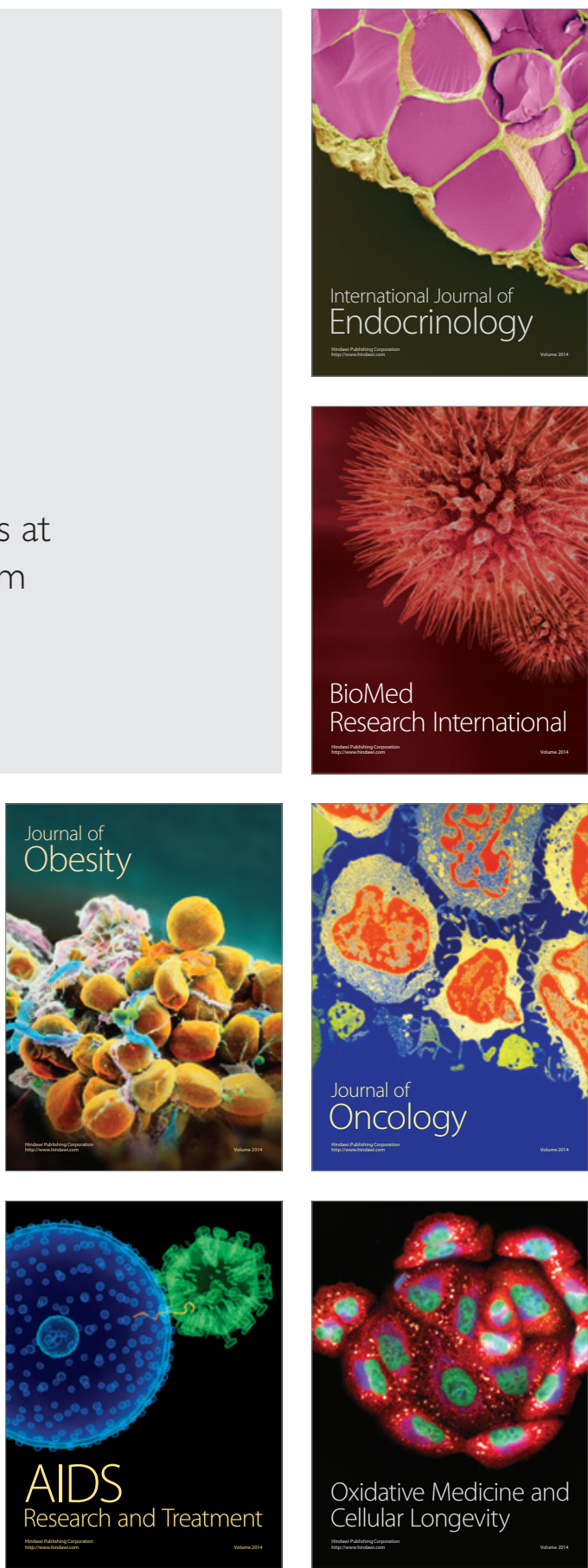